\title{
Direct noninvasive estimation of myocardial tricarboxylic acid cycle flux in vivo using hyperpolarized ${ }^{13} \mathrm{C}$ magnetic resonance
}

\author{
Jessica A.M. Bastiaansen ${ }^{\mathrm{a}, \mathrm{b}, *, 1}$, Tian Cheng ${ }^{\mathrm{b}}$, Hongxia Lei $^{\mathrm{c}}$, Rolf Gruetter ${ }^{\mathrm{a}, \mathrm{c}, \mathrm{d}}$, Arnaud Comment $^{\mathrm{b}}$ \\ a Laboratory of Functional and Metabolic Imaging, Ecole Polytechnique Fédérale de Lausanne, Lausanne, Switzerland \\ b Institute of Physics of Biological Systems, Ecole Polytechnique Fédérale de Lausanne, Lausanne, Switzerland \\ c Department of Radiology, University of Geneva, Geneva, Switzerland \\ d Department of Radiology, University of Lausanne, Lausanne, Switzerland
}

\section{A R T I C L E I N F O}

\section{Article history:}

Received 14 April 2015

Received in revised form 27 July 2015

Accepted 12 August 2015

Available online 19 August 2015

\section{Keywords:}

Metabolism

Citrate

Acetylcarnitine

Acetate

Dynamic nuclear polarization

\begin{abstract}
A B S T R A C T
Background: The heart relies on continuous energy production and imbalances herein impair cardiac function directly. The tricarboxylic acid (TCA) cycle is the primary means of energy generation in the healthy myocardium, but direct noninvasive quantification of metabolic fluxes is challenging due to the low concentration of most metabolites. Hyperpolarized ${ }^{13} \mathrm{C}$ magnetic resonance spectroscopy (MRS) provides the opportunity to measure cellular metabolism in real time in vivo. The aim of this work was to noninvasively measure myocardial TCA cycle flux $\left(\mathrm{V}_{\mathrm{TCA}}\right)$ in vivo within a single minute.

Methods and results: Hyperpolarized $\left[1-{ }^{13} \mathrm{C}\right]$ acetate was administered at different concentrations in healthy rats. ${ }^{13} \mathrm{C}$ incorporation into $\left[1-{ }^{13} \mathrm{C}\right]$ acetylcarnitine and the TCA cycle intermediate $\left[5-{ }^{13} \mathrm{C}\right]$ citrate was dynamically detected in vivo with a time resolution of $3 \mathrm{~s}$. Different kinetic models were established and evaluated to determine the metabolic fluxes by simultaneously fitting the evolution of the ${ }^{13} \mathrm{C}$ labeling in acetate, acetylcarnitine, and citrate. $V_{\text {TCA }}$ was estimated to be $6.7 \pm 1.7 \mu \mathrm{mol} \cdot \mathrm{g}^{-1} \cdot \min ^{-1}$ (dry weight), and was best estimated with a model using only the labeling in citrate and acetylcarnitine, independent of the precursor. The TCA cycle rate was not linear with the citrate-to-acetate metabolite ratio, and could thus not be quantified using a ratiometric approach. The ${ }^{13} \mathrm{C}$ signal evolution of citrate, i.e. citrate formation was independent of the amount of injected acetate, while the ${ }^{13} \mathrm{C}$ signal evolution of acetylcarnitine revealed a dose dependency with the injected acetate. The ${ }^{13} \mathrm{C}$ labeling of citrate did not correlate to that of acetylcarnitine, leading to the hypothesis that acetylcarnitine formation is not an indication of mitochondrial TCA cycle activity in the heart.

Conclusions: Hyperpolarized $\left[1-{ }^{13} \mathrm{C}\right]$ acetate is a metabolic probe independent of pyruvate dehydrogenase (PDH) activity. It allows the direct estimation of $\mathrm{V}_{\mathrm{TCA}}$ in vivo, which was shown to be neither dependent on the administered acetate dose nor on the ${ }^{13} \mathrm{C}$ labeling of acetylcarnitine. Dynamic ${ }^{13} \mathrm{C}$ MRS coupled to the injection of hyperpolarized $\left[1-{ }^{13} \mathrm{C}\right]$ acetate can enable the measurement of metabolic changes during impaired heart function.
\end{abstract} (c) 2015 Elsevier Ltd. All rights reserved.

\section{Introduction}

To ensure contractile performance and support myocardial workload, the heart is in continuous need for energy sources that can supply

Abbreviations: AcetylCoA, acetyl coenzyme A; ACS, acetylCoA synthetase; ATL, acetylcarnitine translocase; CAT, carnitine acetyltransferase; TCA, tricarboxylic acid; $V_{\text {TCA }}$ TCA cycle flux; DNP, dynamic nuclear polarization; MRI, magnetic resonance imaging; MRS, magnetic resonance spectroscopy; PDH, pyruvate dehydrogenase; PET, positron emission tomography; RF, radiofrequency; WALTZ, wideband alternating-phase lowpower technique for zero-residual splitting; FASTESTMAP, fast, automatic shim technique using echo-planar signal readout for mapping along projections.

* Corresponding author at: Laboratory of Functional and Metabolic Imaging, LIFMETIPSB-SB, Ecole Polytechnique Fédérale de Lausanne, Station 6, 1015 Lausanne, Switzerland.

E-mail address: jbastiaansen.mri@gmail.com (J.A.M. Bastiaansen).

1 Present address: Department of Radiology, University Hospital Lausanne (CHUV) and University of Lausanne (UNIL), Center for Biomedical Imaging (CIBM), Lausanne, Switzerland. adenosine triphosphate (ATP). A large fraction of myocardial ATP is generated through the tricarboxylic acid (TCA) cycle, the rate of which reflects the myocardial oxygen consumption [1]. Since the flux through the TCA cycle $\left(\mathrm{V}_{\mathrm{TCA}}\right)$ is tightly linked to the mechanical workload of the heart, variations in $\mathrm{V}_{\mathrm{TCA}}$ are indicative of impaired myocardial metabolism and function. In the healthy myocardium, fatty acids are the preferred metabolic substrates but the propensity of the heart to extract energy from this type of fuel can be strongly altered in cardiac diseases. Acetate, although not a physiological substrate for the heart, has been shown to be a revealing tracer for assessing myocardial oxidative metabolism via positron emission tomography (PET) [2] and ${ }^{13} \mathrm{C}$ magnetic resonance spectroscopy (MRS) $[1,3,4]$. It is the shortest fatty acid and its uptake into the heart occurs through simple diffusion, its exchange between plasma and tissue only depending on the concentration gradient [5]. It is an effective oxidizable substrate formed endogenously that can be activated to acetylCoA via cytosolic or mitochondrial acetylCoA 
synthetase [6,7]. The cytosolic variant of acetylCoA synthetase is mainly present in the liver, while the mitochondrial variant is abundant in the heart and muscle and provides acetylCoA that is utilized mainly for oxidation under ketogenic conditions [7]. AcetylCoA enters the tricarboxylic acid (TCA) cycle as citrate via an irreversible condensation with oxaloacetate catalyzed by citrate synthase. Since the inner mitochondrial membrane is impermeable to acetylCoA, an excess in acetylCoA can be transferred to the cytosol via a carnitine mediated acetyltransferase system [8]. The conversion of acetylCoA to acetylcarnitine is catalyzed by carnitine acetyl transferase (CAT), an enzyme largely found in heart mitochondria, peroxisomes, the endoplasmic reticular lumen but not in the cytosol $[9,10]$. The shuttling of acetylcarnitine across mitochondrial membranes is an exchange process mediated by acetylcarnitine translocase (ATL). The reported absence of CAT from the cytosol, may suggest two metabolic routes of acetate, (i) passing by the peroxisomal centers to enter the mitochondria as acetylcarnitine, or (ii) a direct entry via mitochondrial ACS. There have been conflicting reports on the involvement of CAT and acetylcarnitine in the transfer of acetyl groups from peroxisomes to the cytosol as discussed in [11], and therefore the conversion of acetate to acetylCoA via mitochondrial ACS seems most likely (Fig. 1).

The dynamic aspect of in vivo ${ }^{13} \mathrm{C}$ MRS following metabolic substrate injection and its large chemical shift range, can provide unique insights into the metabolic state of the heart [1,12-15]. However, because of their inherent low concentrations, TCA cycle intermediates cannot be detected in vivo using thermally polarized ${ }^{13} \mathrm{C}$-labeled substrates. Instead, $\mathrm{V}_{\mathrm{TCA}}$ is estimated from the kinetics of incorporation of ${ }^{13} \mathrm{C}$ labels into glutamate via an isotopic exchange with 2-oxoglutarate $[13,14,16,17]$. This indirect assessment not only involves TCA cycle activity, but also the oxoglutarate-malate carrier, since a large portion of the detected glutamate is located in the cytosol $[18,19]$. Therefore, variations observed in the ${ }^{13} \mathrm{C}$ labeling dynamics of glutamate may indicate perturbations in metabolic intermediate pool size changes or membrane transport as in the ischemia-reperfusion model, where it was found that the rate of glutamate labeling decreased while $\mathrm{V}_{\mathrm{TCA}}$

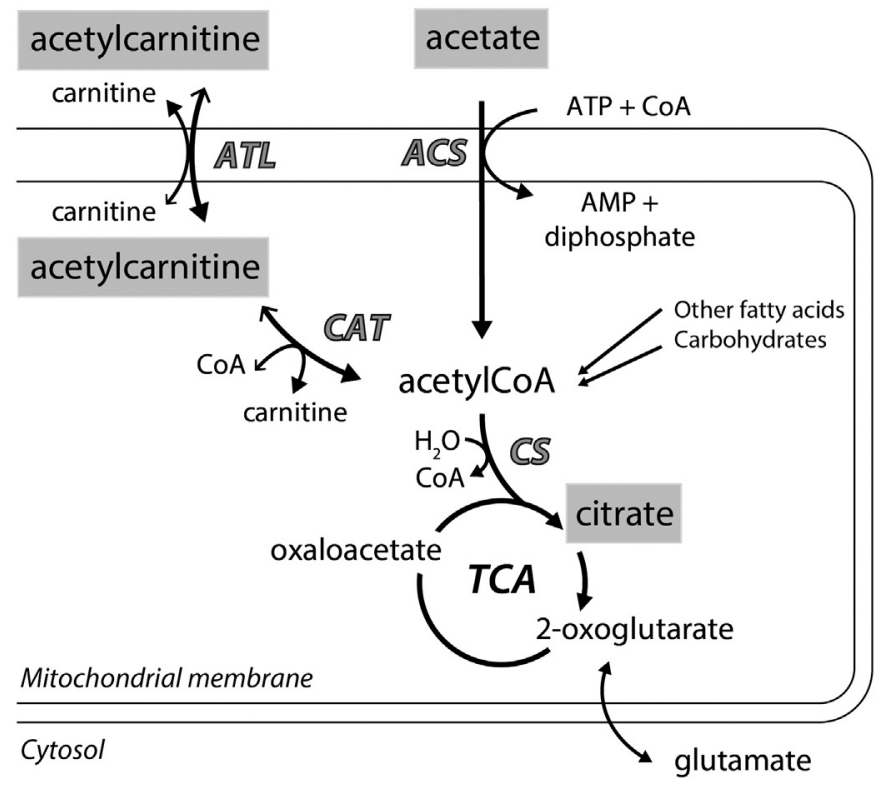

Fig. 1. Diagram of acetate metabolism in the healthy myocardium, depicting the propagation of the ${ }^{13} \mathrm{C}$ labeling. Upon entering the cardiomyocyte, acetate is transformed to acetylCoA via acetylCoA synthetase (ACS). Carnitine acetyltransferase (CAT) converts acetylCoA to acetylcarnitine. Acetylcarnitine translocase (ATL) transports the acetylcarnitine into the mitochondrion. Citrate synthase (CS), the activity of which determines the TCA cycle flux, condenses oxaloacetate with acetylCoA to form citrate. The grey boxes indicate the ${ }^{13} \mathrm{C}$ labeled metabolites which were detected in this study, namely $\left[1-{ }^{13} \mathrm{C}\right]$ acetate, $\left[1-{ }^{13} \mathrm{C}\right]$ acetylcarnitine and $\left[5-{ }^{13} \mathrm{C}\right]$ citrate. remained normal [20]. The measurement of label incorporation into TCA cycle intermediates such as citrate, which is predominantly mitochondrial, would enable a direct estimation of $\mathrm{V}_{\text {TCA. }}$.

Hyperpolarization via dissolution dynamic nuclear polarization (DNP) increases the sensitivity of ${ }^{13} \mathrm{C}$ MRS by several orders of magnitude and allows for the detection of less abundant metabolites in vivo [21]. The technique provides unique insights into important questions regarding myocardial metabolism, substrate preference, pharmacological intervention, and the ability to differentiate between normal and pathological metabolism [22-33]. Pyruvate is by far the most widely used hyperpolarized ${ }^{13} \mathrm{C}$ substrate and it can be served as a probe for mitochondrial oxidative flux [34]. The entry of the ${ }^{13} \mathrm{C}$ label into the TCA cycle via acetylCoA is however dependent on the flux through pyruvate dehydrogenase (PDH), an enzyme that is tightly regulated and will hinder the direct assessment of $\mathrm{V}_{\text {TCA }}$. Unlike pyruvate, acetate uptake is independent of PDH activity. A study of hyperpolarized $\left[1-{ }^{13} \mathrm{C}\right]$ acetate metabolism in resting rat skeletal muscle showed that the rate of acetylcarnitine ${ }^{13} \mathrm{C}$ labeling can be directly translated to the metabolic flux through ACS [35]. However, despite the fact that $\left[1-{ }^{13} \mathrm{C}\right]$ acetylCoA was detected in the mouse heart and liver following the injection of hyperpolarized $\left[1-{ }^{13} \mathrm{C}\right.$ ]acetate $[36],{ }^{13} \mathrm{C}$ label incorporation from acetate into myocardial TCA cycle intermediates has to date not been reported in vivo. This is most likely due to their low concentration combined with their spectral proximity to the large ${ }^{13} \mathrm{C}$ resonance of the injected precursor. This is supported by the in vivo data obtained following the injection of hyperpolarized $\left[1-{ }^{13} \mathrm{C}\right]$ butyrate in which citrate was clearly observed [32,37].

The aim of the present study was to take advantage of the sensitivity gain provided by hyperpolarization together with an increased chemical-shift resolution at high field to determine, in a single oneminute ${ }^{13} \mathrm{C}$ MRS experiment, myocardial TCA cycle flux in vivo using hyperpolarized $\left[1-{ }^{13} \mathrm{C}\right]$ acetate as a metabolic substrate.

\section{Methods}

\subsection{Animals}

All animal experiments were conducted according to the Swiss federal ethical guidelines and were approved by the local regulatory body. Male Sprague Dawley rats (300 g) were anesthetized with $1.5 \%$ isoflurane in oxygen $(n=12)$. A catheter was placed into the femoral vein for intravenous delivery of the acetate solution. A second catheter was placed in the artery to monitor the blood pressure, which was used as a cardiac triggering signal and for blood sampling. Animals were placed and immobilized in a homebuilt holder to minimize potential motion during MRI and MRS acquisitions. Body temperature was maintained at $37^{\circ} \mathrm{C}$ using a warm water circulation system. Arterial blood pressure, heart rate, and respiratory rate were continuously monitored with an animal monitoring system (SA Instruments, NY, USA). Arterial $\mathrm{pH}$ and pressures of $\mathrm{O}_{2}$ and $\mathrm{CO}_{2}$ were measured using a blood gas analyzer (AVL Compact 3, Diamond Diagnostics, MA, USA). The rate-pressure-product (RPP) was determined from the arterial blood pressure and the heart rate. A summary of physiological parameters can be found in Table 1 .

Table 1

Summary of physiological parameters $(\mathrm{n}=12)$.

\begin{tabular}{lc}
\hline Heart rate $\left(\mathrm{min}^{-1}\right)$ & $367 \pm 17$ \\
Systolic pressure $(\mathrm{mm} \mathrm{Hg})$ & $135 \pm 28$ \\
Diastolic pressure $(\mathrm{mm} \mathrm{Hg})$ & $101 \pm 33$ \\
Rate pressure product $(\mathrm{mm} \mathrm{Hg} \mathrm{min}$ & \pm 1 ) \\
Respiration rate $\left(\mathrm{min}^{-1}\right)$ & $50969 \pm 11,811$ \\
$\mathrm{pH}$ & $63 \pm 8$ \\
$\mathrm{pCO}_{2}$ & $7.39 \pm 0.02$ \\
$\mathrm{pO}_{2}$ & $37.5 \pm 4.4$ \\
\hline
\end{tabular}




\subsection{Sample preparation and hyperpolarization protocol}

Unless otherwise specified, all chemicals were purchased from Sigma-Aldrich (Buchs, Switzerland). Sodium $\left[1-{ }^{13} \mathrm{C}\right]$ acetate was dissolved to a concentration of $4.5 \mathrm{M}$ in a 1:2 mixture of fully deuterated ethanol $\left(\mathrm{d}_{6}\right.$-EtOD) and water $\left(\mathrm{D}_{2} \mathrm{O}\right)$ containing $33 \mathrm{mM}$ of TEMPO (2,2,6,6-tetramethylpiperidine-1-oxyl) free radical. A total volume of $300 \mu \mathrm{L}$ of this solution was inserted, in the form of $10 \mu \mathrm{L}$ frozen beads (prepared in liquid nitrogen), into a $5 \mathrm{~T}$ custom-designed DNP polarizer prefilled with liquid helium [38]. The ${ }^{13} \mathrm{C}$ nuclei were dynamically polarized for $2 \mathrm{~h}$ at $1.15 \mathrm{~K}$. Following a previously described automated process [39], the beads were rapidly dissolved in $6 \mathrm{~mL}$ of pressurized, heated $\mathrm{D}_{2} \mathrm{O}$ and the resulting solution was transferred within $2 \mathrm{~s}$ into a separator/infusion pump located inside an actively shielded 31-cm diameter horizontal bore 9.4 T magnet (Magnex Scientific, Abingdon, UK) [40]. The separator/infusion pump was prefilled with $0.6 \mathrm{~mL}$ of phosphate buffered saline and heparin. Subsequently, $1.0 \mathrm{~mL}$ of solution at physiological temperature and $\mathrm{pH}$, with a ${ }^{13} \mathrm{C}$ polarization level of $13 \pm 2 \%$, was automatically injected into the femoral vein of the anesthetized animal in $5 \mathrm{~s}$. To determine the influence of the administrated amount of acetate, the $1.0 \mathrm{~mL}$ bolus of hyperpolarized $\left[1-{ }^{13} \mathrm{C}\right]$ acetate was injected at a dose ranging from 0.3 to $1.0 \mathrm{mmol} / \mathrm{kg}$.

\subsection{In vivo MRI and MRS}

All ${ }^{13} \mathrm{C}$ MRS and ${ }^{1} \mathrm{H}$ magnetic resonance imaging (MRI) measurements were carried out at $9.4 \mathrm{~T}$ with a Direct Drive spectrometer (Agilent, Palo Alto, CA, USA). A home-built ${ }^{13} \mathrm{C} /{ }^{1} \mathrm{H}$ probe, consisting of a pair of $10 \mathrm{~mm}$ diameter ${ }^{13} \mathrm{C}$ surface coils in quadrature mode and a single $10 \mathrm{~mm}$ diameter ${ }^{1} \mathrm{H}$ surface coil, was placed over the rat chest, localizing signal from the cardiac muscle. A hollow glass sphere with a $3 \mathrm{~mm}$ inner diameter (Wilmad-LabGlass, NJ, USA) was filled with an aqueous $1 \mathrm{M}\left[1-{ }^{13} \mathrm{C}\right]$ glucose solution and used to adjust the radiofrequency ( $R F$ ) excitation pulse power and set the reference frequency. Once the animal was positioned inside the magnet, ten axial $1 \mathrm{~mm}$ thick slices were acquired using a nontriggered gradient echo sequence (repetition time: $\mathrm{T}_{\mathrm{R}}=50 \mathrm{~ms}$; echo time: $\mathrm{T}_{\mathrm{E}}=3 \mathrm{~ms}$; field of view: $\mathrm{FOV}=30 \times 30 \mathrm{~mm}^{2}$; matrix size: $128 \times 128$; flip angle: $\theta=30^{\circ}$; number of averages: $\left.N A=8\right)$ from which the correct position of the animal was determined. This was followed by the acquisition of cinematographic images (FOV = $40 \times 40 \mathrm{~mm}^{2}$; matrix size: $256 \times 256 ; \mathrm{T}_{\mathrm{R}}=140 \mathrm{~ms} ; \mathrm{T}_{\mathrm{E}}=4.5 \mathrm{~ms}$; $\mathrm{NA}=8$; number of frames: 14 ; slice thickness: $1 \mathrm{~mm}$ ) to confirm and set the timing of the cardiac trigger in the end-diastolic phase. The cardiac trigger was typically send 50 or $60 \mathrm{~ms}$ after the maximum observed blood pressure. Cardiac triggered and respiratory gated shimming was performed to reduce the localized proton line width in a myocardial voxel of $4 \times 5 \times 5 \mathrm{~mm}^{3}$ to $20-30 \mathrm{~Hz}$ using a triggered FASTESTMAP sequence [41], resulting in a non-localized proton line width of $80-120 \mathrm{~Hz}$. The spectrometer was triggered to start acquisition at the beginning of the automated injection process. Series of single pulse acquisitions were sequentially recorded using $30^{\circ}$ adiabatic RF excitation pulses (BIR-4) [42], with ${ }^{1} \mathrm{H}$ decoupling using WALTZ [43]. Free induction decays were acquired with 4129 complex data points over a $20 \mathrm{kHz}$ bandwidth. All acquisitions were cardiac triggered and respiratory gated, resulting in a nominal $T_{R}$ between 3 and $3.5 \mathrm{~s}$. The adiabatic pulse offset and power were calibrated to ensure that the RF excitation angle $\theta=30^{\circ}$ for all observed metabolites in the entire tissue of interest. Following in vivo data acquisition, a $200 \mu \mathrm{L}$ liquid sample was extracted from the separator/infusion pump to retrospectively determine the precise injected $\left[1-{ }^{13} \mathrm{C}\right]$ acetate concentration [35]. The blood volume of the animals was obtained using the relation between total blood volume and body weight published by Lee and Blaufox [44] allowing calculation of the blood ${ }^{13} \mathrm{C}$ acetate concentration.

\subsection{Data analysis}

A non-linear least-squares quantification algorithm (AMARES) implemented in the jMRUI software package was used to fit the dynamic ${ }^{13} \mathrm{C}$ MRS data [45]. The spectra were corrected for the phase and DC offset. Soft constraints were imposed to peak frequencies (182.55$182.65 \mathrm{ppm}$ for acetate, $173.85-173.95 \mathrm{ppm}$ for acetylcarnitine, and 179.65-179.75 ppm for citrate) and line widths (FWHM $=10-30 \mathrm{~Hz}$ ), and the relative phases were fixed to zero.

The time courses of the quantified peak areas were analyzed with Matlab (The MathWorks, Natick, MA, USA) using the kinetic models described in the next sections. Correlation matrices indicative of the extent to which free parameters affect each other were calculated for all analyses. The signal decay of precursor and metabolites results from a combination of the effects of longitudinal relaxation (characterized by the time constant $T_{1}$ ), RF excitation, and biochemical conversion and all time courses were corrected for the effect of repeated RF excitations. The $T_{1}$ of $\left[1-{ }^{13} \mathrm{C}\right.$ ]acetylcarnitine was set to $14.9 \mathrm{~s}$, as previously determined in vivo [35], and that of $\left[5^{-13} \mathrm{C}\right]$ citrate to $20 \mathrm{~s}$ [46]. The acetate signal decay was treated as free parameter. The ${ }^{13} \mathrm{C}$ labeling of acetate entering the myocardium was treated as an instantaneous enrichment to its maximum value using an exponential function.

\subsection{Kinetic model of myocardial acetate metabolism}

A kinetic model describing the dynamic ${ }^{13} \mathrm{C}$ labeling pattern following the metabolism of $\left[1-{ }^{13} \mathrm{C}\right]$ acetate (Fig. 1) was implemented. It consists of a system of coupled differential equations that can be depicted by a box diagram (Fig. 2A) and are described as follows:

$$
\begin{aligned}
& \frac{\mathrm{d}}{\mathrm{dt}}{ }^{13} \mathrm{ACE}=-\mathrm{V}_{\mathrm{ACS}} \frac{{ }^{13} \mathrm{ACE}}{\mathrm{ACE}}, \\
& \frac{\mathrm{d}}{\mathrm{dt}}{ }^{13} \mathrm{COA}=\mathrm{V}_{\mathrm{ACS}} \frac{{ }^{13} \mathrm{ACE}}{\mathrm{ACE}}-\mathrm{V}_{\mathrm{CAT}}^{\mathrm{f}} \frac{{ }^{13} \mathrm{COA}}{\mathrm{COA}}+\mathrm{V}_{\mathrm{CAT}}^{\mathrm{b}} \frac{{ }^{13} \mathrm{CAR}}{\mathrm{CAR}}-\mathrm{V}_{\mathrm{CS}} \frac{{ }^{13} \mathrm{COA}}{\mathrm{COA}}, \\
& \frac{\mathrm{d}}{\mathrm{dt}}{ }^{13} \mathrm{CAR}=\mathrm{V}_{\mathrm{CAT}}^{\mathrm{f}} \frac{{ }^{13} \mathrm{COA}}{\mathrm{COA}}-\mathrm{V}_{\mathrm{CAT}}^{\mathrm{b}} \frac{{ }^{13} \mathrm{CAR}}{\mathrm{CAR}}, \\
& \frac{\mathrm{d}}{\mathrm{dt}}{ }^{13} \mathrm{CIT}=\mathrm{V}_{\mathrm{CS}} \frac{{ }^{13} \mathrm{COA}}{\mathrm{COA}}-\mathrm{V}_{\mathrm{TCA}} \frac{{ }^{13} \mathrm{CIT}}{\mathrm{CIT}} .
\end{aligned}
$$

ACE, COA, CAR, and CIT represent the total metabolic pool size of acetate, acetylCoA, acetylcarnitine, and citrate, respectively. ${ }^{13} \mathrm{ACE},{ }^{13} \mathrm{COA}$, ${ }^{13} \mathrm{CAR}$, and ${ }^{13} \mathrm{CIT}$ represent the size of the corresponding ${ }^{13} \mathrm{C}$-labeled pools. $\mathrm{V}_{\mathrm{ACS}}$ is the flux through ACS, $\mathrm{V}_{\mathrm{CAT}}^{\mathrm{f}}$ and $\mathrm{V}_{\mathrm{CAT}}^{\mathrm{b}}$ are the forward and backward fluxes through CAT, respectively, $\mathrm{V}_{\mathrm{TCA}}$ is the TCA cycle flux, and $\mathrm{V}_{\mathrm{CS}}$ the flux through citrate synthase. By substituting the acetylCoA term $\left(\mathrm{V}_{\mathrm{CAT}}^{\mathrm{f}} \frac{{ }^{13} \mathrm{COA}}{\mathrm{COA}}\right)$ in Eq. (3) using Eq. (2) and by using the small pool size approximation ( $\frac{\mathrm{d}}{\mathrm{dt}}{ }^{13} \mathrm{COA}<<\frac{\mathrm{d}}{\mathrm{dt}}{ }^{13} \mathrm{CAR}$ ) [35] and the assumption that the ${ }^{13} \mathrm{C}$ fractional enrichment of acetylcarnitine is proportional to the one of acetylCoA, i.e. $\frac{{ }^{13} \mathrm{COA}}{\mathrm{COA}}=\alpha \frac{{ }^{13} \mathrm{CAR}}{\mathrm{CAR}}$, which is supported by the rapid ${ }^{13} \mathrm{C}$ exchange between acetylCoA and acetylcarnitine observed by Schroeder et al. [47], the system simplifies to (Fig. 2B):

$\frac{\mathrm{d}}{\mathrm{dt}}{ }^{13} \mathrm{ACE}=-\mathrm{V}_{\mathrm{ACS}} \frac{{ }^{13} \mathrm{ACE}}{\mathrm{ACE}}$,

$\frac{\mathrm{d}}{\mathrm{dt}}{ }^{13} \mathrm{CAR}=\mathrm{V}_{\mathrm{ACS}} \frac{{ }^{13} \mathrm{ACE}}{\mathrm{ACE}}-\mathrm{V}_{\mathrm{IM}} \frac{{ }^{13} \mathrm{CAR}}{\mathrm{CAR}}$,

$\frac{\mathrm{d}}{\mathrm{dt}}{ }^{13} \mathrm{CIT}=\mathrm{V}_{\mathrm{IM}} \frac{{ }^{13} \mathrm{CAR}}{\mathrm{CAR}}-\mathrm{V}_{\mathrm{TCA}} \frac{{ }^{13} \mathrm{CIT}}{\mathrm{CIT}}$,

where the intermediate flux $V_{I M}$ is defined as $\alpha V_{\text {CS. See Supplemental }}$ Methods for a detailed description of the model. The value of $\alpha$ is not 


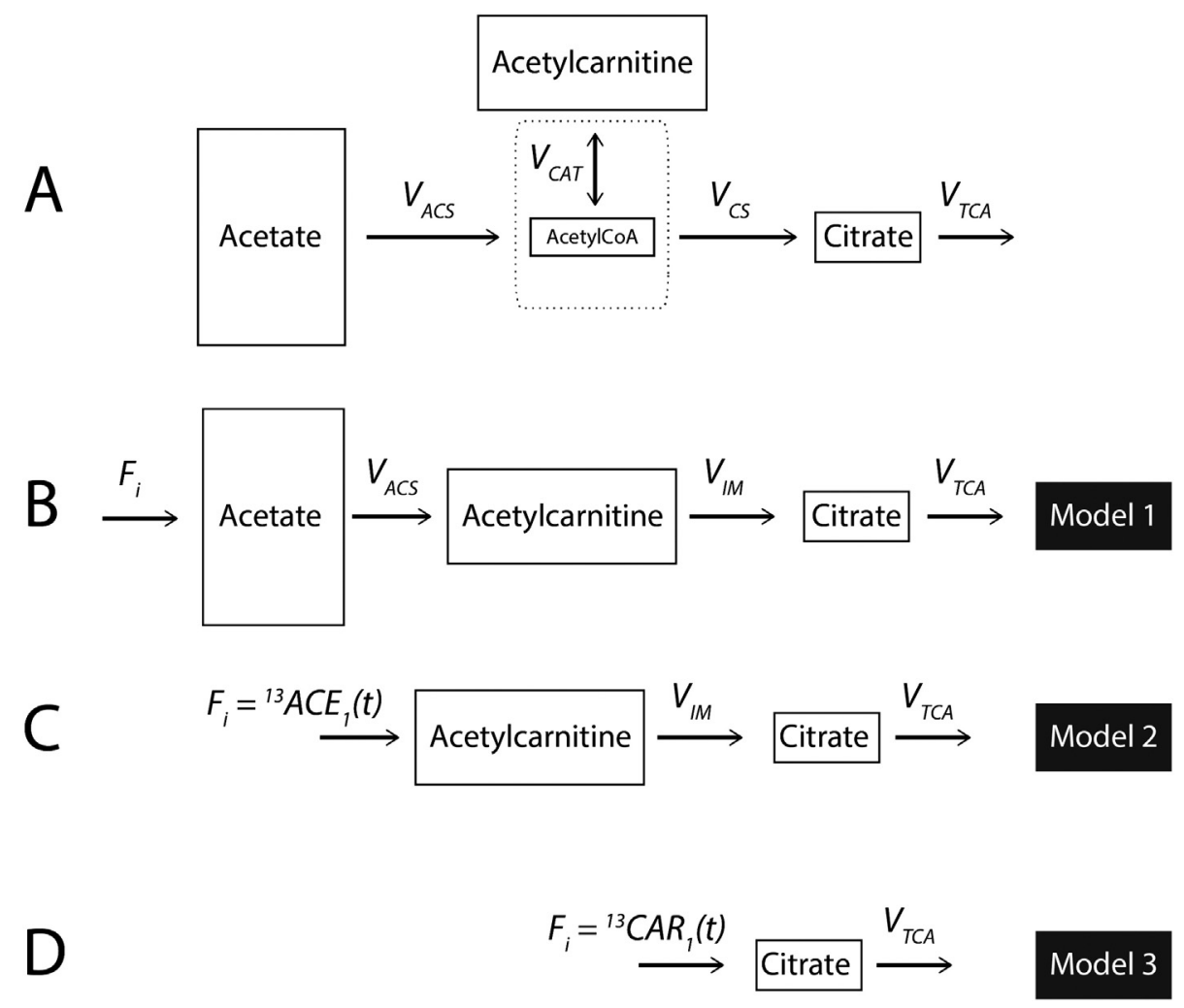

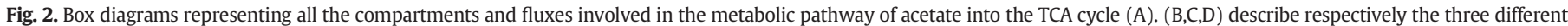

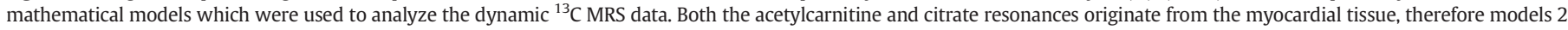

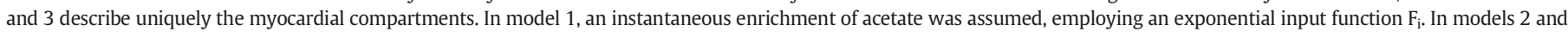
3 , the input function was described by the ${ }^{13} \mathrm{C}$ labeling time course of acetate and acetylcarnitine respectively.

required for determining $\mathrm{V}_{\mathrm{TCA}}$, but based on the previous estimation that $60 \%$ of pyruvate-derived acetylCoA cycled through the acetylcarnitine pool before citrate formation [47], the factor $\alpha$ is expected to be at most $1 / 0.6$.

This mathematical model is an extension of the model we have previously used to analyze hyperpolarized acetate metabolism in skeletal muscle [35] and in the heart [48]. As for most ${ }^{13} \mathrm{C}$ MRS experiments, the signals originating from different cellular compartments cannot be separated and the model assumes that all processes take place within the same cellular compartment. It must however be borne in mind that the pathways through which citrate and acetylcarnitine can be ${ }^{13} \mathrm{C}$-labeled are restricted because of the short experimental time, and although it is very possible that some ${ }^{13} \mathrm{C}$-citrate and ${ }^{13} \mathrm{C}$-acetylcarnitine flow from the mitochondria to the cytosol, they are labeled while located in the mitochondria. In other words, the dynamics of ${ }^{13} \mathrm{C}$ incorporation into citrate and acetylcarnitine is independent of the final location of both metabolites as long as the experiment is short enough for not having them labeled through other pathways, and ultimately the ${ }^{13} \mathrm{C}$ signal that is measured is a direct readout of the ${ }^{13} \mathrm{C}$ incorporation into mitochondrial citrate and acetylcarnitine.

In the heart, the observed acetate signal originates from both tissue and blood, compartments which cannot be distinguished. Three different modeling approaches were investigated (See also Supplemental Methods): in model 1 (Fig. 2B), the three equations (Eqs. (5)-(7)) are used to fit the signal evolution of acetate, acetylcarnitine, and citrate with a total of 5 free parameters, namely, the decay rate of acetate $\left(\mathrm{R}_{1, \mathrm{ACE} 1}\right), \mathrm{V}_{\mathrm{ACS}}, \mathrm{V}_{\mathrm{IM}}, \mathrm{V}_{\mathrm{TCA}}$ and the acetate input function $\mathrm{F}_{\mathrm{i}}$. In model 2 (Fig. 2C), only the time courses of the two downstream metabolites are fitted and the substrate signal is used as an input function, $\mathrm{F}_{\mathrm{i}}={ }^{13} \mathrm{ACE}(\mathrm{t})$, with $\mathrm{V}_{\mathrm{ACS}}, \mathrm{V}_{\mathrm{IM}}$ and $\mathrm{V}_{\mathrm{TCA}}$ as free parameters. In model 3 (Fig. 2D), the citrate signal evolution is solely fitted and the acetylcarnitine is taken as an input function, $\mathrm{F}_{\mathrm{i}}={ }^{13} \mathrm{CAR}_{1}(\mathrm{t})$, with only two free parameters, namely, $\mathrm{V}_{\mathrm{IM}}$ and $\mathrm{V}_{\mathrm{TCA}}$. The mathematical models were adjusted to the ${ }^{13} \mathrm{C}$ curves by non-linear regression using the Levenberg-Marquardt algorithm, coupled to a RungeKutta method to obtain numerical solutions of the ordinary differential equations that define each model. All numerical procedures were performed using Matlab. Fitted parameters are reported with standard deviation.

The concentration of citrate was set to $1.48 \mu \mathrm{mol} / \mathrm{g}$ dry weight, as determined in healthy male Sprague Dawley rats fed ad libitum and weighing between 300 and $400 \mathrm{~g}$ [49], i.e., in animals having precisely the same specifications as those used in the present study. Note that pool sizes might differ in animals with different metabolic states or disease and should be modified accordingly. A wet/dry weight ratio of 5.29 was assumed [50]. The pool sizes of acetate [ACE] and acetylcarnitine [CAR] were not set but incorporated in the estimated kinetic parameters of the model, i.e., $k_{\mathrm{ACS}}=\mathrm{V}_{\mathrm{ACS}} /[\mathrm{ACE}]$ and $k_{\mathrm{IM}}=\mathrm{V}_{\mathrm{IM}} /[\mathrm{CAR}]$, due to limited evidence of the stability of the ACE and CAR pool sizes during the experiment.

\section{Results}

The metabolism of acetate was detected in the healthy rat myocardium within the first minute after its administration. Following the injection of the hyperpolarized $\left[1-{ }^{13} \mathrm{C}\right]$ acetate bolus, both $\left[1-{ }^{13} \mathrm{C}\right]$ acetylcarnitine and $\left[5-{ }^{13} \mathrm{C}\right]$ citrate were rapidly isotopically enriched and detected in vivo with a time resolution of $3 \mathrm{~s}$ (Fig. 3A). Despite the narrow ${ }^{13} \mathrm{C}$ line widths $(20-40 \mathrm{~Hz})$, it was not possible to detect the $\left[5-{ }^{13} \mathrm{C}\right]$ citrate resonance in 2 out of the $12 \mathrm{ex}$ periments due to the close spectral proximity of the large $\left[1-{ }^{13} \mathrm{C}\right] \mathrm{ac}-$ etate resonance (Fig. 3B and C). The signal integral of the precursor and downstream metabolites were plotted as a function of time 

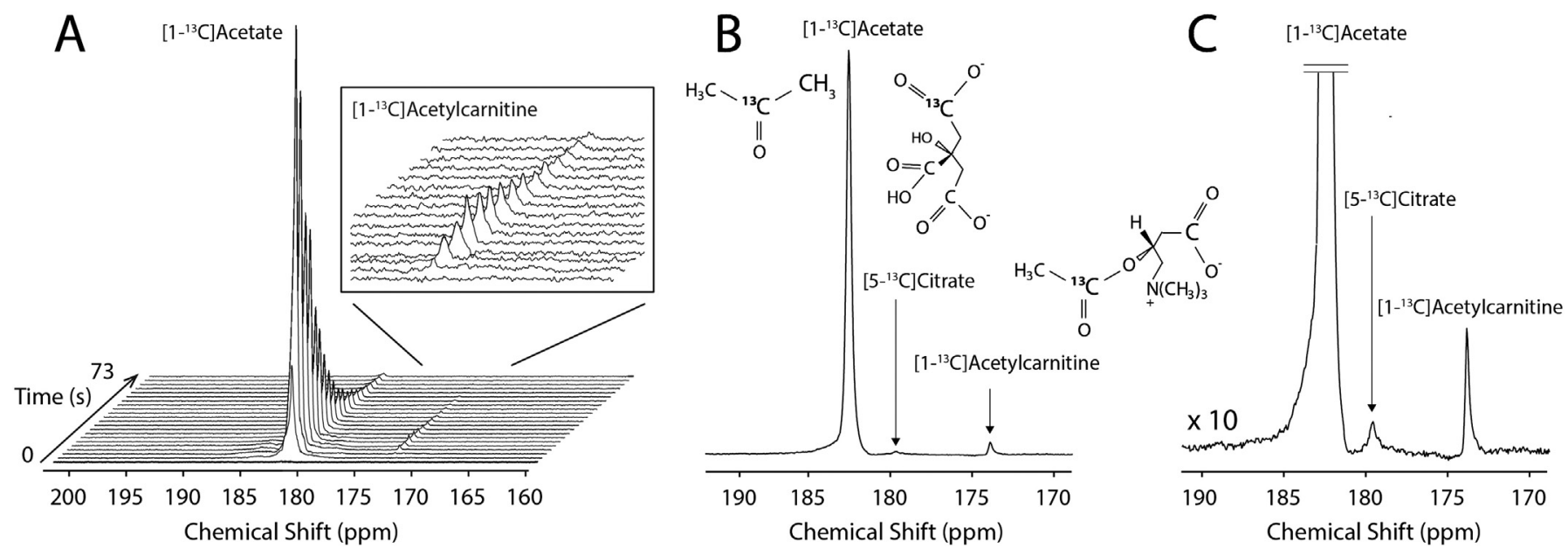

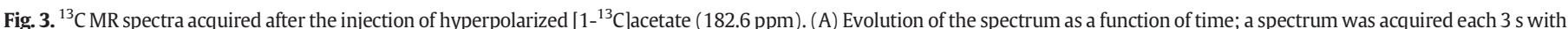

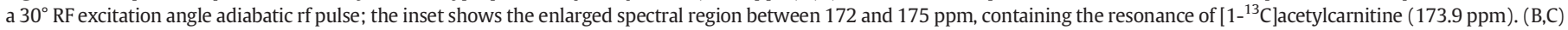
Sum of 4 spectra $(t=21$ to $t=30 \mathrm{~s})$ revealing more clearly the presence of the TCA cycle intermediate $\left[5-{ }^{13} \mathrm{C}\right] \mathrm{citrate}(179.7 \mathrm{ppm})$.

(Fig. 4A and B). The evolution of the $\left[5-{ }^{13} \mathrm{C}\right]$ citrate signal was recorded with sufficient signal-to-noise ratio (SNR), to be significantly above the noise level for 7 out of the 10 experiments in which citrate was detected (SNR larger or equal to 3 in the absence of line broadening). After reaching a maximum signal integral $8 \pm 3 \mathrm{~s}$ after the start of the injection (Fig. $4 \mathrm{~A}$ ), the hyperpolarized $\left[1-{ }^{13} \mathrm{C}\right]$ acetate signal decayed mono-exponentially with a time constant of $9.6 \pm 1.6 \mathrm{~s}$. The maximum acetylcarnitine signal integral was recorded $15 \pm 3 \mathrm{~s}$ after the beginning of the injection and the maximum citrate signal integral approximately $6 \mathrm{~s}$ later (Fig. 4B).

To determine $\mathrm{V}_{\mathrm{TCA}}$, the ACS rate $k_{\mathrm{ACS}}$ and the intermediate rate $k_{\mathrm{IM}}$ as well as the $\left[1-{ }^{13} \mathrm{C}\right]$ acetylcarnitine, $\left[5-{ }^{13} \mathrm{C}\right]$ citrate, and $\left[1-{ }^{13} \mathrm{C}\right]$ acetate signal time courses were simultaneously fitted to each one of the three different mathematical models described in the Methods section. The appropriateness of each model was tested by evaluating the accuracy of each fit as well as the interdependence of fit parameters. The resulting $\mathrm{V}_{\mathrm{TCA}}$ values ranged from $6.7 \pm 1.7$ to $16.4 \pm$ $8.7 \mu \mathrm{mol} \cdot \mathrm{g}^{-1} \cdot \min ^{-1}$ dry weight using model 3 and 1 , respectively (Table 2, Fig. 5A). Although these results vary 3 -fold, the estimation of $V_{\text {TCA }}$ provided by model 3 was clearly less dependent on other fitting parameters and therefore more robust (Fig. S1). This model only fits the dynamics of the formation of citrate while using the time course of acetylcarnitine as an input function. It is therefore independent of the infused substrate acetate and leads to a more consistent estimation of $\mathrm{V}_{\mathrm{TCA}}$.

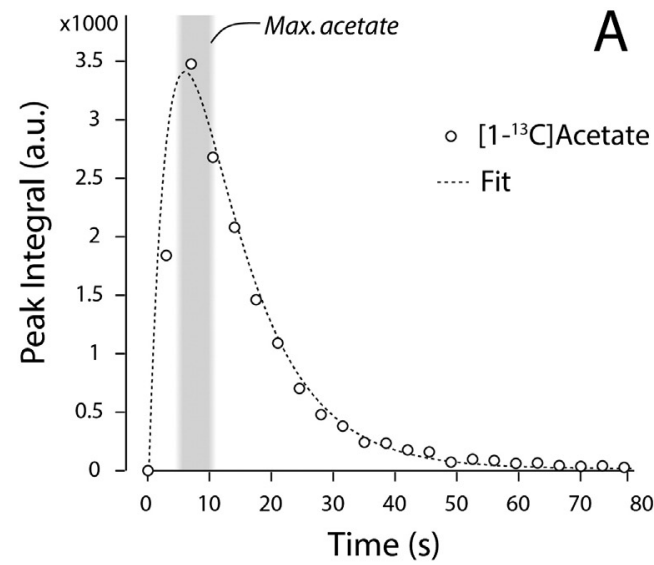

Similar $k_{\mathrm{ACS}}$ values were deduced from both models 1 and 2 , respectively $1.7 \pm 0.4$ and $1.8 \pm 0.4 \mathrm{~ms}^{-1}$ (Table 2, Fig. 5B), and the $k_{\mathrm{IM}}$ extracted from all three models ranged from $24.7 \pm 3.9$ to $37.4 \pm 14.0 \mathrm{~ms}^{-1}$ (Table 2, Fig. 5C). The mean $\mathrm{V}_{\mathrm{TCA}}$ and $k_{\mathrm{IM}}$ values exhibit a clear dependence on the model and their standard deviation decreases with the number of reduced free parameters (Table 2 , Fig. 5). In addition, the correlation matrices show that when the number of free parameters decreases, they become less dependent on one another (Fig. S1). Both these observations support that $k_{\mathrm{IM}}$ and $V_{\text {TCA }}$ were best estimated using model 3. It was observed that neither $\mathrm{V}_{\mathrm{TCA}}$ nor $k_{\mathrm{IM}}$ depends on the amount of injected substrate, but that $k_{\mathrm{ACS}}$ decays with increasing acetate dose, displaying a Michaelis-Menten like trend (Fig. S2A). The acetylcarnitine-toacetate ratio showed a similar trend as function of the injected acetate dose (Fig. S2B) and it scaled linearly with $k_{\text {ACs }}$ (Fig. S3). The citrate-to-acetate ratio did not correlate with the injected acetate dose or with any other determined parameter, showing that a ratiometric approach cannot be used to estimate myocardial $V_{\mathrm{TCA}}$.

\section{Discussion}

This study reports for the first time the direct in vivo detection of a TCA cycle intermediate following myocardial metabolism of acetate. Through the time-resolved measurement of ${ }^{13} \mathrm{C}$ citrate, a direct estimate of the $\mathrm{V}_{\mathrm{TCA}}$ flux could be determined.

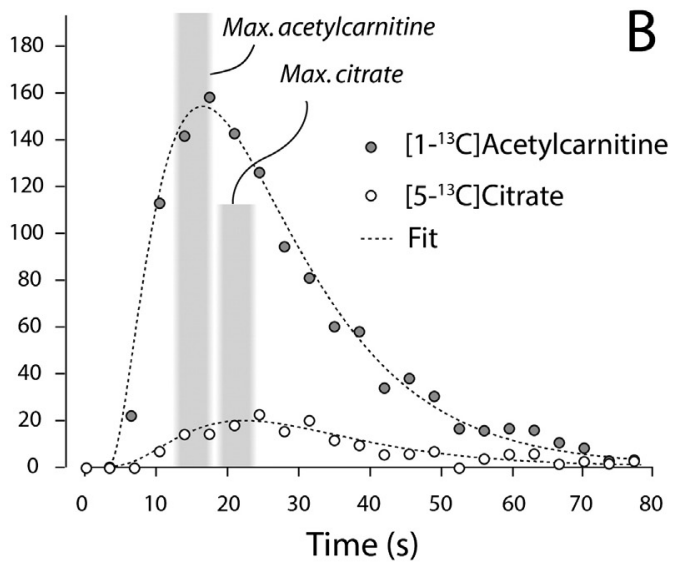

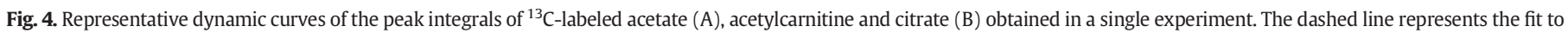
the metabolic model. The grey boxes indicate the average time, \pm one standard deviation, at which the maximum of the respective resonance was observed across all experiments. 
Table 2

Estimated metabolic fluxes and rates found using the three described kinetic models. Data are given as mean values \pm SEM with the corresponding percentage errors in brackets. The spread as well as the error percentage of the estimated kinetic parameters decreased with the reduced number of free parameters. According to the calculated correlation matrixes (Fig. S1), model 3 estimates $\mathrm{V}_{\mathrm{TCA}}$ with the least influence of the other estimated parameters. Note that model 3 only incorporates the labeling of myocardial metabolites and $k_{\text {ACs }}$ was therefore not determined since the dynamics of the acetate signal was not taken into account.

\begin{tabular}{lccl}
\hline & \multicolumn{3}{l}{ Kinetic model } \\
\cline { 2 - 4 } Parameter & $1(\mathrm{n}=7)$ & $2(\mathrm{n}=7)$ & $3(\mathrm{n}=7)$ \\
\hline $\mathrm{V}_{\mathrm{TCA}}\left(\mu \mathrm{mol} \cdot \mathrm{g}^{-1} \cdot \mathrm{min}^{-1}\right.$ & $16.4 \pm 8.7$ & $9.0 \pm 3.9$ & $6.7 \pm 1.7$ \\
$\mathrm{dry}$ weight $)$ & $(53 \%)$ & $(43 \%)$ & $(25 \%)$ \\
$\mathrm{k}_{\mathrm{IM}}\left(\mathrm{ms}^{-1}\right)$ & $37.4 \pm 14.0$ & $28.6 \pm 7.3$ & $24.7 \pm 3.9$ \\
& $(37 \%)$ & $(25 \%)$ & $(16 \%)$ \\
$\mathrm{k}_{\mathrm{ACS}}\left(\mathrm{ms}^{-1}\right)$ & $1.7 \pm 0.4$ & $1.8 \pm 0.4$ & - \\
& $(22 \%)$ & $(20 \%)$ & \\
\hline
\end{tabular}

As in most hyperpolarized ${ }^{13} \mathrm{C}$ MRS experiments, elevated substrate concentrations were required. In this study, the estimated maximum plasma concentration at the end of the bolus injection was between 3 and $15 \mathrm{mM}$, which immediately decayed after the bolus injection. In previous metabolic studies, 45 min-long acetate infusions have been used, leading to plasma concentrations up to $10 \mathrm{mM}$ [16,51], and no adverse effects were reported in hyperpolarized MR studies with comparable doses of ${ }^{13} \mathrm{C}$-acetate $[35,36,52-54]$. In the present study, all monitored physiological parameters remained stable before and after injection (Table 1 ), and no adverse effects were observed following acetate administration.

In contrast to earlier investigations in cardiac muscle performed at $2.35 \mathrm{~T}$ or $3 \mathrm{~T}[36,52,54]$, the increased spectral resolution obtained at $9.4 \mathrm{~T}$ allowed for the direct observation of the $\left[5-{ }^{13} \mathrm{C}\right]$ citrate resonance, and illustrates the benefit and need for high field. The delayed observation of citrate with respect to acetylcarnitine is consistent with the role of carnitine as a shuttle for acetyl groups across the mitochondrial membrane, and as a mitochondrial buffer for excess
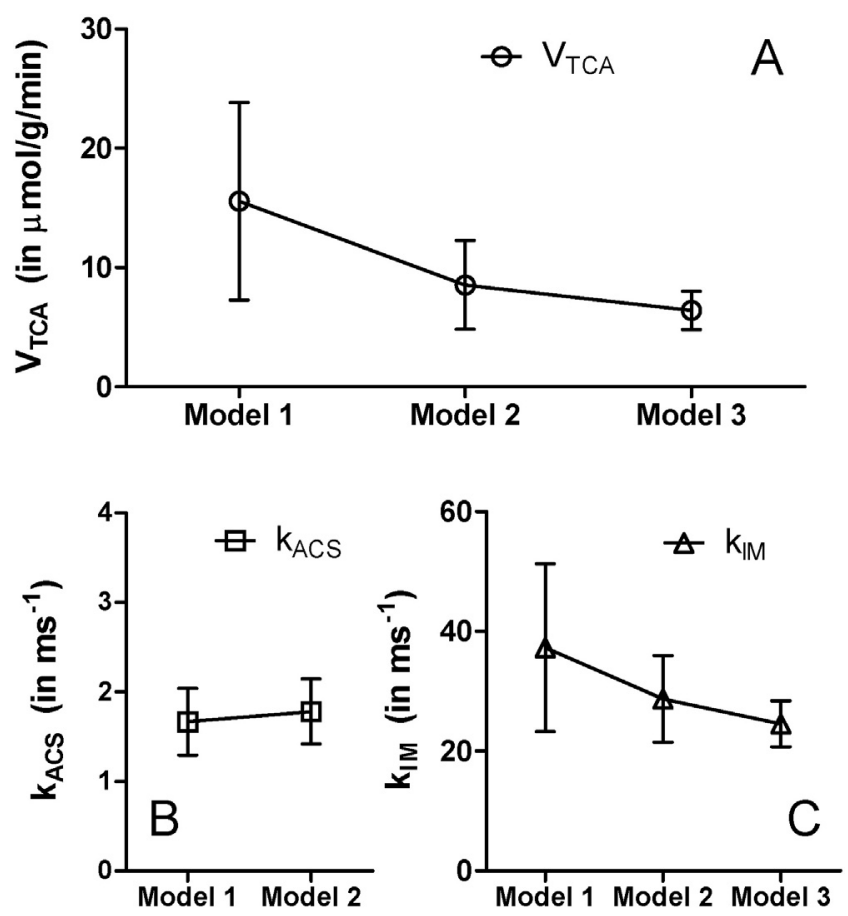

Fig. 5. Metabolic fluxes and rates estimated $(n=7)$ using three different kinetic models of myocardial acetate metabolism. Error bars indicate \pm SEM. As the number of free parameters decreases, the standard deviation of the estimated kinetic parameter $k_{\mathrm{IM}}$ and the $\mathrm{V}_{\mathrm{TCA}}$ flux decreases as well.
acetylCoA. A similar evolution of the ${ }^{13} \mathrm{C}$ labeling of citrate was detected using the hyperpolarized carbohydrate $\left[2-{ }^{13} \mathrm{C}\right]$ pyruvate [55]. However, in these studies the mitochondrial uptake of pyruvate is mediated by PDH where acetylcarnitine acts as a buffer for excess acetylCoA, which was shown to be a rapid exchange process [56].

The acetylCoA resonance previously reported at $202 \mathrm{ppm}$ after a $90^{\circ}$ excitation in the mouse heart following the injection of hyperpolarized $\left[1-{ }^{13} \mathrm{C}\right]$ acetate could not be detected in the present study [36]. Detectable quantities of ${ }^{13} \mathrm{C}$-labeled glutamate could be expected since $60 \%$ of the ${ }^{14} \mathrm{C}$ activity measured 2 min after the injection of ${ }^{14} \mathrm{C}$-labeled acetate was associated with glutamate while a mere $8 \%$ was found to come from TCA cycle metabolites [57]. It was nevertheless not possible to detect the $\left[5-{ }^{13} \mathrm{C}\right]$ glutamate resonance in our experiments which was ascribed to the close proximity of the large $\left[1-{ }^{13} \mathrm{C}\right]$ acetate resonance (the glutamate resonance is expected 0.1-0.2 ppm upfield from the acetate resonance). It must be borne in mind that it should be possible to further increase the sensitivity of these experiments by enhancing the initial polarization level of the ${ }^{13} \mathrm{C}$ nucleus through the improvement of the acetate substrate preparation [58,59].

The myocardial $V_{\text {TCA }}$ was estimated using the three different kinetic models. Two of the proposed models do not directly take into account the dynamics of the injected substrate and only depend on the evolution of the acetylcarnitine and citrate signals, which originate from the tissue compartment. By excluding the time evolution of the acetate signal, a substantial part of which originates from the vascular compartment, it was observed that the estimation of the metabolic parameters is affected (Table 2). Additionally, it was observed that the parameters determining the acetate signal evolution did not correlate with the kinetic parameters related to acetylcarnitine and citrate ${ }^{13} \mathrm{C}$ labeling (Fig. S1), showing that the acetylcarnitine and citrate signal evolution are independent of the bolus dynamics of the injected substrate. The ${ }^{13} \mathrm{C}$ labeling kinetics of $\left[1-{ }^{13} \mathrm{C}\right]$ acetylcarnitine was however found to be dependent on the dose of injected hyperpolarized $\left[1-{ }^{13} \mathrm{C}\right]$ acetate. This dose dependence is consistent with the role of mitochondrial carnitine acetyltransferase and acetylcarnitine as buffer system for intramitochondrial acetylCoA. A similar dose dependence was reported in a previous study in rat skeletal muscle from which the in vivo ACS MichaelisMenten parameters could be derived [35]. Michaelis-Menten parameters were not determined in the present work because of the large contribution of the ventricular compartment to the acetate signal. A ratiometric analysis of hyperpolarized acetate metabolism was also performed in the earlier skeletal muscle study, showing that metabolic rates and fluxes can be estimated without the need for mathematical modeling [35]. A linear relationship between $k_{\mathrm{Acs}}$ and the acetylcarnitine-to-acetate ratio was indeed observed, leading to a simple mathematical definition to convert the acetylcarnitine-toacetate ratio to a kinetic rate constant $k_{A C S}$. In the present study, a linear relationship was also observed, but only between the acetylcarnitineto-acetate ratio and $k_{A C S}$. This suggests that a ratiometric approach is appropriate to analyze the ACS activity. However, no correlation between the evolution of the citrate signal and the acetylcarnitine or acetate signal could be detected. A possible explanation for this absence of correlation might be related to the potential increase of the acetylCoA pool resulting from the large amount of injected acetate that could lead to the sequestration of CoA. Since no acetylCoA signal was detected and because of the rate limiting role of ACS previously observed [35], it is rather hypothesized that the discrepancy is due to the fact that it is not possible to separate the acetylcarnitine signals originating from the cytosolic and mitochondrial compartments, which are very likely to have a different ${ }^{13} \mathrm{C}$ labeling dynamics. Regardless of the reason behind this absence of correlation, it indicates that it is not possible to use a ratiometric approach to derive $\mathrm{V}_{\mathrm{TCA}}$ and that the kinetics of the acetylcarnitine signal cannot be used as a marker of mitochondrial oxidative metabolism. Note that the use of adiabatic excitation pulses provided identical excitation and detection for all metabolites and enabled observation of true ratios independent of their location in 
the sensitive volume of the ${ }^{13} \mathrm{C}$ coil. Although single pulses without encoded spatial localization were used for data acquisition, potential signal contamination from the superficial muscle was excluded due to difference in kinetics of acetylcarnitine and absence of ${ }^{13} \mathrm{C}$ citrate in an earlier study performed in skeletal muscle [35], as well as the absence of the ${ }^{13} \mathrm{C}$ acetylcarnitine resonance in the chest muscle in ${ }^{13} \mathrm{C}$ images of acetylcarnitine [52]. It has to be noted that if there would be contamination from surrounding muscle tissue, this would only attribute to the ${ }^{13} \mathrm{C}$ acetylcarnitine signal. Since the estimation of $\mathrm{V}_{\text {TCA }}$ is independent on the kinetics of ${ }^{13} \mathrm{C}$ acetylcarnitine using model 3 , which is only dependent on the ${ }^{13} \mathrm{C}$ citrate signal evolution, model 3 is most robust for ${ }^{13} \mathrm{C}$ localization or compartmentation uncertainties.

In ${ }^{13} \mathrm{C}$ MRS studies, information about endogenous pool sizes is necessary to derive quantitative metabolic fluxes. These pool sizes can change as a result of diseases, altered nutritional states such as fasting [60], or substrate injection, especially during the long infusion times necessary to perform thermally-polarized ${ }^{13} \mathrm{C}$ MRS experiments. In the present hyperpolarized ${ }^{13} \mathrm{C}$ MRS study, downstream metabolic pool sizes were most likely not notably modified within the 30$60 \mathrm{~s}$ following the injection of the acetate bolus, i.e., within the time window of the measurements. This is again supported by the rate limiting role of ACS on acetate metabolism [35]. Based on this hypothesis and using the previously determined citrate concentration ( $1.48 \mu \mathrm{mol} / \mathrm{g}$ dry weight) [49], $\mathrm{V}_{\mathrm{TCA}}$ was estimated to be $6.7 \pm$ $1.7 \mu \mathrm{mol} \cdot \mathrm{g}^{-1} \cdot \mathrm{min}^{-1}$ (dry weight). Although this value is comparable to previously published fluxes determined from ${ }^{13} \mathrm{C}$ MRS or radioactive labeled carbon experiments performed during a long acetate infusion in perfused heart or in vivo and typically leading to $\mathrm{V}_{\mathrm{TCA}}$ comprised between 7.4 and $14 \mu \mathrm{mol} \cdot \mathrm{g}^{-1} \cdot \mathrm{min}^{-1}$ (dry weight) $[3,15,16,61]$, the values estimated in the present work correspond to the lower end of the range. This might at first appear counter-intuitive since the RPP recorded in this in vivo study ( $50 \mathrm{k} \mathrm{mm} \mathrm{Hg} \mathrm{min}^{-1}$; Table 1$)$ was significantly larger than the reported RPP in earlier studies ( $20 \mathrm{k}$ to $30 \mathrm{k} \mathrm{mm} \mathrm{Hg} \mathrm{min}^{-1}$ ) [3,15], and a larger $\mathrm{V}_{\text {TCA }}$ is usually expected with increased RPP.

A limitation of the present work is the absence of comparison with a gold standard method such as the measurement of oxygen consumption rate $\left(\mathrm{MVO}_{2}\right)$. Although reporting similar $\mathrm{V}_{\mathrm{TCA}}$, the obtained $\mathrm{MVO}_{2}$ varied between 16 (in vivo [15]) and 29 to $31 \mu \mathrm{mol} \cdot \mathrm{g}^{-1} \cdot \mathrm{min}^{-1}$ (dry weight) (in perfused heart $[3,16,61])$, suggesting a more efficient energy conversion in vivo. Future studies should incorporate such a comparison to validate the estimated values of $\mathrm{V}_{\mathrm{TCA}}$ obtained in the present study.

It is hypothesized that the low $\mathrm{V}_{\mathrm{TCA}}$ measured in the present study could be a consequence of the drastically shorter time of hyperpolarized ${ }^{13} \mathrm{C}$ MRS experiments as compared to thermally-polarized ${ }^{13} \mathrm{C}$ MRS or radioactively labeled carbon experiments. This might imply that variations in $\mathrm{V}_{\mathrm{TCA}}$ resulting from myocardial conditioning to the infused substrate can be neglected, which highlight the potential benefit of the short time frame of hyperpolarized ${ }^{13} \mathrm{C}$ experiments for cardiac studies.

\section{Conclusion}

We showed that it is possible to estimate myocardial $\mathrm{V}_{\mathrm{TCA}}$ in vivo through the time-resolved ${ }^{13} \mathrm{C}$ MRS measurement of $\left[5-{ }^{13} \mathrm{C}\right]$ citrate following the injection of hyperpolarized $\left[1-{ }^{13} \mathrm{C}\right]$ acetate. $\mathrm{V}_{\mathrm{TCA}}$ and the dynamics of ${ }^{13} \mathrm{C}$ citrate labeling were independent on the amount of injected substrate and did not correlate with the dynamics of ${ }^{13} \mathrm{C}$ acetylcarnitine labeling. The resulting $\mathrm{V}_{\mathrm{TCA}}$ value is similar to values previously determined indirectly through the several-hour measurements of glutamate ${ }^{13} \mathrm{C}$ labeling, although the results obtained through hyperpolarized ${ }^{13} \mathrm{C}$ MRS might be more accurate because it provides an almost instantaneous readout after the injection of the non-physiological dose of acetate. We expect that dynamic ${ }^{13} \mathrm{C}$ MRS coupled to the injection of hyperpolarized $\left[1-{ }^{13} \mathrm{C}\right]$ acetate can enable the measurement of metabolic changes during impaired heart function.

Fatty acid metabolism could ideally be probed with longer-chain substrates such as palmitate in order to provide information on the dynamics of beta oxidation. However, although in vivo butyrate and octanoate metabolism was measured in the rat heart by hyperpolarized ${ }^{13} \mathrm{C}$ MR $[32,37,62]$, their shorter $\mathrm{T}_{1}$ as compared to acetate limits even more the sensitivity and therefore the possibility for translation to human applications.

The clinical potential of hyperpolarized MR is widely recognized, in particular in cancer research [63], and the first trial in patients using $\left[1-{ }^{13} \mathrm{C}\right]$ pyruvate demonstrated that this technology can provide unique metabolic information for diagnostic purposes [64]. The foreseen applications in cardiac imaging and their expected impact in cardiology have been recently discussed [65-67]. Although hyperpolarized $\left[1-{ }^{13} \mathrm{C}\right]$ acetate would be a unique probe to determine $V_{\text {TCA }}$ in humans, it would require the use of a high-field MR scanner and high-order shim coils to resolve the $\left[5-{ }^{13} \mathrm{C}\right]$ citrate peak. Considering the rather rapid spread of $7 \mathrm{~T}$ human MRI technology, it is nevertheless not excluded that the method herein proposed could be one day translated for human applications.

\section{Funding sources}

This work was supported by the Swiss National Science Foundation (grant 200020_124901 to R.G. and PP00P2_133562 to A.C.), the National Competence Center in Biomedical Imaging (NCCBI), the Centre d'Imagerie BioMédicale (CIBM) of the UNIL, UNIGE, HUG, CHUV, EPFL, the Leenaards Foundation and the Jeantet Foundation.

\section{Disclosures}

None.

\section{Competing interests}

The authors declare that they have no competing interests.

\section{Acknowledgments}

We thank Hanne Frenkel, Jacquelina Romero, Laure Bardouillet, and Mario Lepore for the veterinary support.

\section{Appendix A. Supplementary data}

Supplementary data to this article can be found online at http://dx. doi.org/10.1016/j.yjmcc.2015.08.012.

\section{References}

[1] R.G. Weiss, S.T. Gloth, R. Kalil, V.P. Chacko, M.D. Stern, G. Gerstenblith, Indexing tricarboxylic-acid cycle flux in intact hearts by C-13 nuclear-magnetic-resonance, Circ. Res. 70 (2) (1992) 392-408.

[2] R. Schulz, C. Kappeler, H. Coenen, A. Bockisch, G. Heusch, Positron emission tomography analysis of [1-(11)C]acetate kinetics in short-term hibernating myocardium, Circulation 97 (10) (1998) 1009-1016.

[3] E.M. Chance, S.H. Seeholzer, K. Kobayashi, J.R. Williamson, Mathematical-analysis of isotope labeling in the citric-acid cycle with applications to C-13 NMR-studies in perfused rat hearts, J. Biol. Chem. 258 (22) (1983) 3785-3794.

[4] C.R. Malloy, A.D. Sherry, F.M.H. Jeffrey, Carbon flux through citric-acid cycle pathways in perfused heart by C-13 NMR-spectroscopy, FEBS Lett. 212 (1) (1987) $58-62$.

[5] B. Mittendorfer, L.S. Sidossis, E. Walser, D.L. Chinkes, R.R. Wolfe, Regional acetate kinetics and oxidation in human volunteers, Am. J. Physiol. Endocrinol. Metab. 274 (6) (1998) E978-E983.

[6] A. Luong, V.C. Hannah, M.S. Brown, J.L. Goldstein, Molecular characterization of human acetyl-CoA synthetase, an enzyme regulated by sterol regulatory elementbinding proteins, J. Biol. Chem. 275 (34) (2000) 26458-26466.

[7] T. Fujino, J. Kondo, M. Ishikawa, K. Morikawa, T.T. Yamamoto, Acetyl-CoA synthetase 2 , a mitochondrial matrix enzyme involved in the oxidation of acetate, J. Biol. Chem. 276 (14) (2001) 11420-11426. 
[8] I.B. Fritz, K.T. Yue, Effects of carnitine on acetyl-CoA oxidation by heart muscle mitochondria, Am. J. Physiol. 206 (1964) 531-535.

[9] A.S. Abbas, G. Wu, H. Schulz, Carnitine acetyltransferase is not a cytosolic enzyme in rat heart and therefore cannot function in the energy-linked regulation of cardiac fatty acid oxidation, J. Mol. Cell. Cardiol. 30 (7) (1998) 1305-1309.

[10] R.R. Ramsay, V.A. Zammit, Carnitine acyltransferases and their influence on CoA pools in health and disease, Mol. Asp. Med. 25 (5-6) (2004) 475-493.

[11] F. Bian, T. Kasumov, K.R. Thomas, K.A. Jobbins, F. David, P.E. Minkler, C.L. Hoppel, H. Brunengraber, Peroxisomal and mitochondrial oxidation of fatty acids in the heart, assessed from the ${ }^{13} \mathrm{C}$ labeling of malonyl-CoA and the acetyl moiety of citrate, J. Biol. Chem. 280 (10) (2005) 9265-9271.

[12] R.G. Weiss, V.P. Chacko, J.D. Glickson, G. Gerstenblith, Comparative C-13 and P-31 NMR assessment of altered metabolism during graded reductions in coronary flow in intact rat hearts, Proc. Natl. Acad. Sci. U. S. A. 86 (16) (1989) 6426-6430.

[13] C.R. Malloy, A.D. Sherry, F.M.H. Jeffrey, Evaluation of carbon flux and substrate selection through alternate pathways involving the citric-acid cycle of the heart by $\mathrm{C}-13$ NMR-spectroscopy, J. Biol. Chem. 263 (15) (1988) 6964-6971.

[14] C.R. Malloy, F.M.H. Jeffrey, A.D. Sherry, Analysis of multiple pathways of substrate metabolism in the citric-acid cycle of the heart, Circulation 74 (4) (1986) 435-435.

[15] A. Ziegler, C.E. Zaugg, P.T. Buser, J. Seelig, B. Kunnecke, Non-invasive measurements of myocardial carbon metabolism using in vivo ${ }^{13} \mathrm{C}$ NMR spectroscopy, NMR Biomed. 15 (3) (2002) 222-234.

[16] P.J. Randle, P.J. England, R.M. Denton, Control of tricarboxylate cycle and its interactions with glycolysis during acetate utilization in rat heart, Biochem. J. 117 (4) (1970) 677-695.

[17] J.C. Chatham, J.R. Forder, J.D. Glickson, E.M. Chance, Calculation of absolute metabolic flux and the elucidation of the pathways of glutamate labeling in perfused rat-heart by C-13 NMR-spectroscopy and nonlinear least-squares analysis, J. Biol. Chem. 270 (14) (1995) 7999-8008.

[18] K. Lanoue, W.J. Nicklas, J.R. Williams, Control of citric acid cycle activity in rat heart mitochondria, J. Biol. Chem. 245 (1) (1970) 102-111

[19] X. Yu, L.T. White, C. Doumen, L.A. Damico, K.F. LaNoue, N.M. Alpert, E.D. Lewandowski, Kinetic analysis of dynamic C-13 NMR spectra: metabolic flux, regulation, and compartmentation in hearts, Biophys. J. 69 (5) (1995) 2090-2102.

[20] E.D. Lewandowski, X. Yu, K.F. LaNoue, L.T. White, C. Doumen, J.M. ODonnell, Altered metabolite exchange between subcellular compartments in intact postischemic rabbit hearts, Circ. Res. 81 (2) (1997) 165-175.

[21] J.H. Ardenkjaer-Larsen, B. Fridlund, A. Gram, G. Hansson, L. Hansson, M.H. Lerche, R. Servin, M. Thaning, K. Golman, Increase in signal-to-noise ratio of $>10,000$ times in liquid-state NMR, Proc. Natl. Acad. Sci. U. S. A. 100 (18) (2003) 10158-10163.

[22] M.A. Schroeder, L.E. Cochlin, L.C. Heather, K. Clarke, G.K. Radda, D.J. Tyler, In vivo assessment of pyruvate dehydrogenase flux in the heart using hyperpolarized carbon13 magnetic resonance, Proc. Natl. Acad. Sci. U. S. A. 105 (33) (2008) 12051-12056.

[23] M.E. Merritt, C. Harrison, C. Storey, F.M. Jeffrey, A.D. Sherry, C.R. Malloy, Hyperpolarized ${ }^{13} \mathrm{C}$ allows a direct measure of flux through a single enzymecatalyzed step by NMR, Proc. Natl. Acad. Sci. U. S. A. 104 (50) (2007) 19773-19777.

[24] K. Golman, J.S. Petersson, P. Magnusson, E. Johansson, P. Akeson, C.M. Chai, G. Hansson, S. Mansson, Cardiac metabolism measured noninvasively by hyperpolarized C-13 MRI, Magn. Reson. Med. 59 (5) (2008) 1005-1013.

[25] M.S. Dodd, D.R. Ball, M.A. Schroeder, L.M. Le Page, H.J. Atherton, L.C. Heather, A.M. Seymour, H. Ashrafian, H. Watkins, K. Clarke, et al., In vivo alterations in cardiac metabolism and function in the spontaneously hypertensive rat heart, Cardiovasc. Res. 95 (1) (2012) 69-76.

[26] H.J. Atherton, M.S. Dodd, L.C. Heather, M.A. Schroeder, J.L. Griffin, G.K. Radda, K. Clarke, D.J. Tyler, Role of pyruvate dehydrogenase inhibition in the development of hypertrophy in the hyperthyroid rat heart: a combined magnetic resonance imaging and hyperpolarized magnetic resonance spectroscopy study, Circulation 123 (22) (2011) 2552-2561.

[27] M.S. Dodd, H.J. Atherton, C.A. Carr, D.J. Stuckey, J.A. West, J.L. Griffin, G.K. Radda, K. Clarke, L.C. Heather, D.J. Tyler, Impaired in vivo mitochondrial Krebs cycle activity after myocardial infarction assessed using hyperpolarized magnetic resonance spectroscopy, Circ. Cardiovasc. Imaging 7 (6) (2014) 895-904.

[28] C. Purmal, B. Kucejova, A.D. Sherry, S.C. Burgess, C.R. Malloy, M.E. Merritt, Propionate stimulates pyruvate oxidation in the presence of acetate, Am. J. Physiol. Heart Circ. Physiol. 307 (8) (2014) H1134-H1141.

[29] K.X. Moreno, S.M. Sabelhaus, M.E. Merritt, A.D. Sherry, C.R. Malloy, Competition of pyruvate with physiological substrates for oxidation by the heart: implications for studies with hyperpolarized $\left[1-{ }^{13} \mathrm{C}\right]$ pyruvate, Am. J. Physiol. Heart Circ. Physiol. 298 (5) (2010) H1556-H1564.

[30] C. Khemtong, N.R. Carpenter, L.L. Lumata, M.E. Merritt, K.X. Moreno, Z. Kovacs, C.R. Malloy, A.D. Sherry, Hyperpolarized (13) C NMR detects rapid drug-induced changes in cardiac metabolism, Magn. Reson. Med. 74 (2) (2015) 312-319.

[31] A.M. Seymour, L. Giles, V. Ball, J.J. Miller, K. Clarke, C.A. Carr, D.J. Tyler, In vivo assessment of cardiac metabolism and function in the abdominal aortic banding model of compensated cardiac hypertrophy, Cardiovasc. Res. 106 (2) (2015) 249-260.

[32] J.A. Bastiaansen, M.E. Merritt, A. Comment, Real time measurement of myocardial substrate selection in vivo using hyperpolarized ${ }^{13} \mathrm{C}$ magnetic resonance, J. Cardiovasc. Magn. Reson. 17 (Suppl. 1) (2015) 015.

[33] H. Yoshihara, J.A.M. Bastiaansen, C. Berthonneche, A. Comment, J. Schwitter, Assessing ischemic myocardial metabolism in vivo with hyperpolarized ${ }^{13} \mathrm{C}$ : relating the metabolic perturbation to the area at risk, J. Cardiovasc. Magn. Reson. 17 (1) (2015) 1-2.

[34] A. Comment, M.E. Merritt, Hyperpolarized magnetic resonance as a sensitive detector of metabolic function, Biochemistry 53 (47) (2014) 7333-7357.

[35] J.A.M. Bastiaansen, T. Cheng, M. Mishkovsky, J.M.N. Duarte, A. Comment, R. Gruetter, In vivo enzymatic activity of acetylCoA synthetase in skeletal muscle revealed by ${ }^{13} \mathrm{C}$ turnover from hyperpolarized $\left[1-{ }^{13} \mathrm{C}\right]$ acetate to $\left[1-{ }^{13} \mathrm{C}\right]$ acetylcarnitine, Biochim. Biophys. Acta 1830 (8) (2013) 4171-4178.

[36] P.R. Jensen, T. Peitersen, M. Karlsson, R. In 't Zandt, A. Gisselsson, G. Hansson, S Meier, M.H. Lerche, Tissue-specific short chain fatty acid metabolism and slow metabolic recovery after ischemia from hyperpolarized NMR in vivo, J. Biol. Chem. 284 (52) (2009) 36077-36082.

[37] D.R. Ball, B. Rowlands, M.S. Dodd, L. Le Page, V. Ball, C.A. Carr, K. Clarke, D.J. Tyler, Hyperpolarized butyrate: a metabolic probe of short chain fatty acid metabolism in the heart, Magn. Reson. Med. 71 (5) (2014) 1663-1669.

[38] S. Jannin, A. Comment, F. Kurdzesau, J.A. Konter, P. Hautle, B. van den Brandt, J.J. van der Klink, A $140 \mathrm{GHz}$ prepolarizer for dissolution dynamic nuclear polarization, J. Chem. Phys. 128 (24) (2008).

[39] T. Cheng, M. Mishkovsky, J.A.M. Bastiaansen, O. Ouari, P. Hautle, P. Tordo, B. van den Brandt, A. Comment, Automated transfer and injection of hyperpolarized molecules with polarization measurement prior to in vivo NMR, NMR Biomed. 26 (11) (2013) 1582-1588.

[40] A. Comment, B. van den Brandt, K. Uffmann, F. Kurdzesau, S. Jannin, J.A. Konter, P. Hautle, W.T. Wenckebach, R. Gruetter, J.J. van der Klink, Design and performance of a DNP prepolarizer coupled to a rodent MRI scanner, Concepts Magn. Reson. Part B: Magn. Reson. Eng. 31B (4) (2007) 255-269.

[41] R. Gruetter, I. Tkac, Field mapping without reference scan using asymmetric echoplanar techniques, Magn. Reson. Med. 43 (2) (2000) 319-323.

[42] R.S. Staewen, A.J. Johnson, B.D. Ross, T. Parrish, H. Merkle, M. Garwood, 3-D flash imaging using a single surface coil and a new adiabatic pulse, BIR-4, Investig. Radiol. 25 (5) (1990) 559-567.

[43] A.J. Shaka, J. Keeler, T. Frenkiel, R. Freeman, An improved sequence for broad-band decoupling - WALTZ-16, J. Magn. Reson. 52 (2) (1983) 335-338.

[44] H.B. Lee, M.D. Blaufox, Blood volume in the rat, J. Nucl. Med. 26 (1) (1985) 72-76.

[45] A. Naressi, C. Couturier, J.M. Devos, M. Janssen, C. Mangeat, R. de Beer, D. GraveronDemilly, Java-based graphical user interface for the MRUI quantitation package, MAGMA 12 (2-3) (2001) 141-152.

[46] M. Karlsson, P.R. Jensen, J.O. Duus, S. Meier, M.H. Lerche, Development of dissolution DNP-MR substrates for metabolic research, Appl. Magn. Reson. 43 (1-2) (2012) 223-236.

[47] M.A. Schroeder, H.J. Atherton, M.S. Dodd, P. Lee, L.E. Cochlin, G.K. Radda, K. Clarke D.J. Tyler, The cycling of acetyl-coenzyme a through acetylcarnitine buffers cardiac substrate supply a hyperpolarized C-13 magnetic resonance study, Circ. Cardiovasc. Imaging 5 (2) (2012) 201-209.

[48] J.A.M. Bastiaansen, T. Cheng, R. Gruetter, A. Comment, Proceedings of the 20th Annual Meeting of ISMRM, 2012, p. 4324 (Melbourne, Australia).

[49] J.P. Tessier, B. Thurner, E. Jungling, A. Luckhoff, Y. Fischer, Impairment of glucose metabolism in hearts from rats treated with endotoxin, Cardiovasc. Res. 60 (1) (2003) 119-130.

[50] M.K. Aliev, P. Dos Santos, J.A. Hoerter, S. Soboll, A.N. Tikhonov, V.A. Saks, Water content and its intracellular distribution in intact and saline perfused rat hearts revisited, Cardiovasc. Res. 53 (1) (2002) 48-58.

[51] H. Taegtmeyer, 6 blind men explore an elephant - aspects of fuel metabolism and the control of tricarboxylic-acid cycle activity in heart-muscle, Basic Res. Cardiol. 79 (3) (1984) 322-336.

[52] U. Koellisch, C.V. Gringeri, G. Rancan, E.V. Farell, M.I. Menzel, A. Haase, M. Schwaiger, R.F. Schulte, Metabolic imaging of hyperpolarized [1-13C]acetate and [113C]acetylcarnitine - investigation of the influence of dobutamine induced stress, Magn. Reson. Med. (2014) http://dx.doi.org/10.1002/mrm.25485.

[53] M. Mishkovsky, A. Comment, R. Gruetter, In vivo detection of brain Krebs cycle intermediate by hyperpolarized magnetic resonance, J. Cereb. Blood Flow Metab. 32 (12) (2012) 2108-2113.

[54] A. Flori, M. Liserani, F. Frijia, G. Giovannetti, V. Lionetti, V. Casieri, V. Positano, G.D. Aquaro, F.A. Recchia, M.F. Santarelli, et al., Real-time cardiac metabolism assessed with hyperpolarized [1-(13) C]acetate in a large-animal model, Contrast Media Mol. Imaging 10 (3) (2015) 194-202.

[55] M.A. Schroeder, H.J. Atherton, D.R. Ball, M.A. Cole, L.C. Heather, J.L. Griffin, K. Clarke, G.K. Radda, D.J. Tyler, Real-time assessment of Krebs cycle metabolism using hyperpolarized ${ }^{13} \mathrm{C}$ magnetic resonance spectroscopy, FASEB J. 23 (8) (2009) 2529-2538.

[56] M.A. Schroeder, H.J. Atherton, M.S. Dodd, P. Lee, L.E. Cochlin, G.K. Radda, K. Clarke, D.J. Tyler, The cycling of acetyl-coenzyme A through acetylcarnitine buffers cardiac substrate supply: a hyperpolarized ${ }^{13} \mathrm{C}$ magnetic resonance study, Circ. Cardiovasc Imaging 5 (2) (2012) 201-209.

[57] C.K. Ng, S.C. Huang, H.R. Schelbert, D.B. Buxton, Validation of a model for [1-C-11]Acetate as a tracer of cardiac oxidative-metabolism, Am. J. Physiol. 266 (4) (1994) H1304-H1315.

[58] A. Flori, M. Liserani, S. Bowen, J.H. Ardenkjaer-Larsen, L. Menichetti, Dissolution dynamic nuclear polarization of non-self-glassing agents: spectroscopy and relaxation of hyperpolarized [1- ${ }^{13} \mathrm{C}$ acetate, J. Phys. Chem. A 119 (10) (2015) 1885-1893.

[59] T. Cheng, A. Capozzi, Y. Takado, R. Balzan, A. Comment, Over $35 \%$ liquid-state ${ }^{13} \mathrm{C}$ polarization obtained via dissolution dynamic nuclear polarization at $7 \mathrm{~T}$ and $1 \mathrm{~K}$ using ubiquitous nitroxyl radicals, Phys. Chem. Chem. Phys. 15 (48) (2013) 20819-20822.

[60] J.A.M. Bastiaansen, H.A.I. Yoshihara, Y. Takado, R. Gruetter, A Comment, Hyperpolarized C-13 lactate as a substrate for in vivo metabolic studies in skeletal muscle, Metabolomics 10 (5) (2014) 986-994.

[61] D.B. Buxton, M. Schwaiger, A. Nguyen, M.E. Phelps, H.R. Schelbert, Radiolabeled acetate as a tracer of myocardial tricarboxylic acid cycle flux, Circ. Res. 63 (3) (1988) 628-634.

[62] H. Yoshihara, J. Bastiaansen, M. Karlsson, M. Lerche, A. Comment, J. Schwitter, Myocardial fatty acid metabolism probed with hyperpolarized $\left[1-{ }^{13} \mathrm{C}\right]$ octanoate, $\mathrm{J}$ Cardiovasc. Magn. Reson. 17 (Suppl. 1) (2015) 0101. 
[63] J. Kurhanewicz, D.B. Vigneron, K. Brindle, E.Y. Chekmenev, A. Comment, C.H. Cunningham, R.J. Deberardinis, G.G. Green, M.O. Leach, S.S. Rajan, et al., Analysis of cancer metabolism by imaging hyperpolarized nuclei: prospects for translation to clinical research, Neoplasia 13 (2) (2011) 81-97.

[64] S.J. Nelson, J. Kurhanewicz, D.B. Vigneron, P.E. Larson, A.L. Harzstark, M. Ferrone, M. van Criekinge, J.W. Chang, R. Bok, I. Park, et al., Metabolic imaging of patients with prostate cancer using hyperpolarized $\left[1-{ }^{13} \mathrm{C}\right]$ pyruvate, Sci. Transl. Med. 5 (198) (2013) $198 \mathrm{ra08}$.
[65] C.R. Malloy, M.E. Merritt, A.D. Sherry, Could (13)C MRI assist clinical decisionmaking for patients with heart disease? NMR Biomed. 24 (8) (2011) 973-979.

[66] M.H. Lauritzen, L.V. Sogaard, P.L. Madsen, J.H. Ardenkjaer-Larsen, Hyperpolarized metabolic MR in the study of cardiac function and disease, Curr. Pharm. Des. 20 (2014) 6162-6170.

[67] O.J. Rider, D.J. Tyler, Clinical implications of cardiac hyperpolarized magnetic resonance imaging, J. Cardiovasc. Magn. Reson. 15 (2013) 93. 